\title{
PADLET COMO AMBIENTE VIRTUAL DE APRENDIZAGEM NA FORMAÇÃO DE PROFISSIONAIS DA EDUCAÇÃO
}

1 Dra. Patrícia Grasel da Silva, IFRJ - patricia.grasel@ifrj.edu.br 2 Ms. Dione Sousa de Lima, IFES - dione.lima@ifes.edu.br

Resumo. Diante das possibilidades hipermidiáticas presentes na sociedade em rede, este artigo compartilha a experiência de uso do Padlet, um recurso colaborativo, online e gratuito, como um ambiente virtual de aprendizagem, possibilitando a integração entre professores, alunos e conteúdos em um curso semi-presencial. $O$ artigo tem como cenário de coleta de dados um curso de formação continuada sobre informática instrumental para profissionais da educação básica. Apresenta-se um estudo de caso que dialoga com conceitos sobre cibercultura e virtualização do conhecimento. $O$ estudo caracteriza-se por ser qualitativo, com abordagem metodológica próxima a netnografia, considerando que os dados analisados que encontram-se no ciberespaço (padlet do curso e dos alunos). O envolvimento dos alunos com o Padlet é proveniente do plano de ensino que privilegia a exploração intensiva de atividades através de recursos colaborativos e on-line. Esses recursos possibilitam modelo didático $e$ metodológico em que os alunos trabalham cotidianamente na Internet, articulando teoria e prática. $O$ artigo revela a potencialidade dos recursos on-line e colaborativos como espaços digitais de apoio à formação. Sendo assim, entende-se que ferramentas como Padlet quando utilizados como ambientes virtuais de aprendizagem assumem um papel social que desenvolvem maior autonomia e organização diante da interação com conteúdo.

Palavras-chave: Ambientes Virtuais de Aprendizagem, Formação Continuada, Padlet.

\section{PADLET AS A VIRTUAL LEARNING ENVIRONMENT IN THE EDUCATION PROFESSIONAL TRAINING}

\begin{abstract}
Faced with the hypermedia possibilities present in the network society, this article shares the experience of using Padlet, a collaborative, online and free resource, as a virtual learning environment, allowing the integration between teachers, students and contents in a semi-presential course .The article has as a data collection scenario a continuing education course on instrumental informatics for basic education professionals. A case study is presented that discusses concepts about cyberculture and knowledge virtualization. The study is characterized by being qualitative, with methodological approach close to netnography, considering that the data analyzed are in cyberspace (course and student padlet). The involvement of students with Padlet comes from the teaching plan that privileges intensive exploration of activities through collaborative and online resources. These resources enable a didactic and methodological design in which students work daily on the Internet, articulating theory and practice. The article reveals the potential of online and collaborative resources as digital spaces to support training. Thus, it is understood that tools such as Padlet when used as virtual learning environments assume a social role that develops greater autonomy and organization in the interaction with content.
\end{abstract}

Keywords: Virtual Learning Environments, Continuing Education, Padlet. 


\section{Introdução}

O profissional da educação para trabalhar com tecnologias educacionais precisa desenvolver competências ao longo de sua formação, principalmente relacionadas ao conhecimento e uso de tecnologias, presentes na sociedade atual. Assim, por meio de suas ações, torna-se capaz de oferecer à escola possibilidades de explorar práticas interdisciplinares que proporcionem o encontro de diferentes linguagens emergentes da cultura digital contemporânea. Trata-se de competências de âmbito pedagógico, tecnológico e comunicacional. Competência aqui é compreendida com base nos estudos de Behar (2013), que conceitua como um conjunto de conhecimentos, habilidades e atitudes, o que autora chama de CHA. Para autora o conhecimento vai além da informação, é o conteúdo trabalhado e explorado pelo sujeito. Para autora habilidade trata da materialização do conhecimento colocado em prática. Dessa forma, autora define competência como um conjunto, composta por uma tríade de conhecimento, habilidade e atitude, articulados para solução de problemas. A competência emerge da atitude em busca de resolução.

A sociedade atual é compreendida em um contexto de Cibercultura, em as competências tecnológicas podem ser desenvolvidas diretamente através da interação do sujeito com o objeto digital. O ciberespaço se configura em uma de suas vertentes mais atuantes e controversas, conforme nos lembra Lévy (1999):

\footnotetext{
Internet é um espaço de comunicação propriamente surrealista, do qual nada é excluído, nem o bem, nem o mal, nem suas múltiplas definições, nem discussões... A internet encarna a presença da humanidade a ela própria, já que todas as culturas, todas as disciplinas, todas as paixões aí se entrelaçam. Já que tudo é possível, ela manifesta a conexão do homem com a sua própria essência, que é a aspiração à liberdade. (p. 85)
}

A Cibercultura tem nas tecnologias digitais, suas interfaces de acesso, que estão presentes no cotidiano de todas as esferas sociais, como o trabalho e a educação. Por isto, é preciso enfrentar o inusitado e preparar os profissionais de modo que estejam em sintonia com os tempos atuais.

Ao considerar as mudanças nos processos de ensino e aprendizagem, hoje, mais do que nunca, as instituições de ensino precisam preocupar-se em organizar seus espaços educacionais de acordo com a sociedade atual. Mesmo diante da falta de recursos, é necessário o desenvolvimento de uma fluência digital que promova o surgimento e o aprimoramento de competências, onde exista um olhar para o entorno e a percepção de oportunidades educacionais e profissionais advindas com as tecnologias digitais.

Muitos projetos de cursos não contemplam uma formação adequada para a "Era Digital", pois pautam-se em conteúdos específicos que não são colocados a explorar e/ou usar recursos digitais. No entanto, é fundamental na configuração da cibercultura desenvolver processos formativos permanentes, que devem estabelecer diálogo com a prática docente e o aperfeiçoamento constante, pois, com o advento da Internet, a ciência e a arte de ensinar (Bates, 2016), ganham novas possibilidades, entre as quais destacamos a modalidade a distância, os cursos totalmente on-line, como MOOCs e os cursos híbridos.

A educação a distância, independente de ser $100 \%$ a distância ou semipresencial, é compreendida neste trabalho e definida como uma educação sem distâncias pedagógicas, que faz uso de um ambiente virtual de aprendizagem para 
orientação do estudo, visando auxiliar o aluno a desenvolver autonomia e organização no processo de construção de conhecimento.

\section{Ambientes virtuais de aprendizagem e o Padlet}

Ambiente virtual de aprendizagem (AVA), também conhecidos como e-learning ou plataformas LMS management systems, é compreendido como espaço social e digital e pode ser colaborativo. Possibilita o compartilhamento de diferentes mídias, software, arquivos, linguagens como HTML, 3D Max e outros. No entanto, os ambientes virtuais de aprendizagens não prescindem do professor, mas, preferencialmente, deve possibilitar o monitoramento e acompanhamento técnico e pedagógico do estudo dos alunos.

O Padlet é um recurso para construção de mural virtual, on-line, colaborativo e gratuito. $\mathrm{O}$ recurso possibilita aos usuários curtir, comentar e avaliar as postagens de materiais publicados no mural, além de compartilhar com demais usuários para visualização ou edição do mesmo.

Ferramentas como o Padlet, que apresentam características colaborativas, permitem a interação dos sujeitos difundindo ideias, cultura, democratizando as informações e aprendendo em um contexto diferente do presencial, ou seja, da tradicional sala de aula.

O uso do Padlet como ambiente virtual de aprendizagem não invalida de forma alguma as tradicionais plataformas de educação a distância, apenas contribui para mostrar que há outros recursos colaborativos que também podem potencializar processos formativos no ciberespaço, dependendo do desenho metodológico do curso.

$\mathrm{O}$ recurso escolhido em questão (Padlet) possibilitou o acompanhamento justamente por ser um recurso colaborativo, onde todos os murais virtuais (Padlet) construídos pelos alunos são compartilhados com os professores, com atualização e edição feita pelo autor.

A intenção foi desenvolver um curso em que os momentos assíncronos fossem momentos de navegação do aluno por diferentes recursos hipermidiáticos. Desse modo, optamos por criar um ambiente virtual de aprendizagem no Padlet pautado na linguagem do hipertexto, pois os materiais disponibilizados possibilitam a navegação do aluno por diferentes hiperlinks. Conforme Carlotto (2003, p. 94) a "hipertextualidade é a possibilidade de trânsito dos sujeitos diante dos links da internet." Quanto mais se promove ambientes virtuais de aprendizagens hiperlinkados, mais se promove interação entre sujeito e informação, não há conteúdo fechado, nem planejamento rígido, tudo está por vir e ser construído, de acordo com a navegação de cada aluno.

A formação de professores proposta fez uso da concepção de educação a distância, tendo se estruturado de forma semi-presencial, com encontros intercalados, quinzenais. Todos os planos de aula e materiais de estudo foram disponibilizados no Padlet (http://padlet.com) específico. E todos os alunos foram incentivados à construção do seu espaço digital, para registro de aprendizagens e reflexões sobre as aulas do curso. Cada aluno construiu o seu Padlet e compartilhou com os demais colegas e professores.

\section{Entendendo os conceitos abordados na pesquisa}

Os conceitos que embasam o planejamento do curso e a escolha por um recurso on-line 
e colaborativo - como plataforma de ambiente virtual de aprendizagem - se pautam na compreensão de educação a distância, ensino on-line, ensino híbrido, ciberespaço e virtualização do conhecimento.

Educação a distância (EaD) de acordo com Moore e Kearsley (2011, p. 2) “ ... é o aprendizado planejado que ocorre normalmente em um lugar diferente do local de ensino, exigindo técnicas especiais de criação do curso e de instrução, comunicação por meio de várias tecnologias e disposições organizacionais e administrativas especiais." Educação a distância pode ser compreendida como a forma de educação na qual professores e alunos estão distantes geograficamente e, através de um espaço virtual específico, desenvolvendo uma relação de ensino e aprendizagem. A modalidade de $\mathrm{EaD}$ que exploramos foi semi-presencial, mas que fez uso semanalmente nos encontros presenciais e virtuais do Padlet, como plataforma de apoio, que serviu de recurso para mediação do processo de construção do conhecimento dos alunos.

Ensino on-line tem relação direta com as escolhas metodológicas do curso desenvolvido, justamente por compreender que o ensino on-line teve origem fora do espaço da sala de aula, e não como uma solução imediata para ensinar diferentes áreas de conhecimento. $\mathrm{O}$ ensino on-line começou com aumento de aplicativos que possibilitam o fácil e rápido acesso de informação quando o aluno está em circunstâncias em que não há presença física do professor. Ensino on-line revela, inclusive, o potencial de recursos de curta informação como um canal de comunicação eficaz com sujeitos em espaços digitais. Entendemos que organizar um curso em um espaço digital on-line e colaborativo direcionaria os recursos a serem utilizados e evidenciaria a informação. Justamente por ser um espaço informal de educação, não sendo considerado formalmente uma plataforma para LMS. Horn e Staker (2016, p 32) falam que " ensino on-line está melhorando contínua e previsivelmente, na medida em que busca atender a usuários mais exigentes em situações mais difíceis."

O desenho metodológico do curso se caracteriza na modalidade educação a distância, que teve amparo teórico na potência do ensino on-line, justamente por impactar no comportamento dos alunos diante da mídia utilizada para compartilhar o objeto de conhecimento. Por ter os encontros semi-presenciais, em que todos os encontros foram planejados com apoio de recursos digitais, o curso também perpassa pelo conceito de ensino híbrido, que de acordo com Horn e Staker (2016, p 34) "... é qualquer programa educacional formal no qual um estudante aprende, pelo menos em parte, por meio do ensino on-line, com algum elemento de controle do estudante sobre o tempo, o lugar, o caminho e/ou ritmo."

A aprendizagem desenvolvida a partir da interação do sujeito no ciberespaço é definida por Grasel e Carvalho (2009) como virtualização do conhecimento, que trata do conhecimento sobre tecnologias que estão latentes no sujeito e quando esse sujeito é exposto ao uso de recursos tecnológicos esses conhecimentos se potencializam, emergem. Para Lévy (1996, p.17)

O virtual está constituído em estado latente, pronto a se transformar no real, como por exemplo, a semente de uma árvore. A árvore está na semente, mas no atual momento não está aparecendo, mas nem por isso, deixa de ser real. O virtual não é algo pronto e estático, é considerado como um nó de tendências, de força e potência que provoca o processo de resolução, é como a passagem do possível para o real, ampliando espaços e tempo.

Virtualização do conhecimento contempla o ser/acontecer dos sujeitos no ciberespaço, suas trajetórias e trânsito no contexto digital, tanto nas ações sociais quanto 
profissionais. Castells (1999, p. 41) fala que "nossas sociedades estão cada vez mais estruturadas em uma oposição bipolar entre a Rede e o Ser". Isso revela que através dos recursos disponíveis pela web os processos de formação humana são também processos de transformação social, pois quando os sujeitos interagem com "novos" espaços, ambientes e recursos, a virtualização do conhecimento emerge materializando a cultura digital.

O conteúdo central do curso foi informática instrumental e informática na educação, que transita pelo conceito de Ciberespaço, como lugar potencializador de uma cultura emergente das tecnologias da informação e comunicação. Trata-se de uma outra relação entre tecnologia e sociabilidade, que configura uma cultura digital. No ciberespaço podem acontecer diferentes práticas sociais de troca e compartilhamento de informação, movimentos e manifestos sociais e ampliação do networking. Essas ações são consequência dos recursos tecnológicos que alteram profundamente os processos de comunicação, construção e produção de conhecimento.

Os aspectos teóricos apresentados servem para justificar a escolha metodológica do Padlet como ambiente virtual de aprendizagem. Drucker (1993) desde a década de 90 já alertava que "as tecnologias são importante principalmente porque forçam um "fazer coisas novas" e não simplesmente qualificam as coisas velhas."

\section{Metodologias da pesquisa}

O artigo trata de um recorte de uma pesquisa sobre formação pedagógica no ciberespaço, do grupo de Tecnologias Educacionais e Educação a Distância, na linha de educação, desenvolvimento e cultura digital.

O curso de informática instrumental foi pensado e implementado para profissionais que atuam em escolas, principalmente públicas, da região metropolitana do Rio de Janeiro, e que, todavia, ainda não possuíam conhecimento básico de uso do computador para atividades simples, como uso de e-mail, recursos das nuvens, navegação na web entre outros. As primeiras turmas do curso, referentes aos períodos 2017/2 e 2018/1, foram compostas por aproximadamente 20 profissionais da educação em cada edição, com duração de 52 horas, 26 presenciaise 26 a distância.

A pesquisa caracteriza-se por ser qualitativa, com dados coletados e analisados dentro da perspectiva próxima da netnografia. Os dados foram obtidos nos Padlet construídos pelos próprios alunos e no Padlet construído pelos professores do curso. A amostra no artigo específico foi referente a turma do período 2018/1, alunos atuantes no ensino fundamental da educação básica, na rede pública do estado do Rio de Janeiro.

A coleta de dados aconteceu em etapas: 1) primeiramente visitação in loco nas escolas em que os professores atuam, justamente para compreender o contexto em que os sujeitos da pesquisa estavam inseridos; 2) primeira versão do curso (2017/2), momento em que foi identifica as carências e necessidades referente ao uso de ferramentas básicas da informática para cotidiano profissional; 3) análise e escolha do espaço digital que seria utilizado como ambiente virtual de aprendizagem; 4) segunda versão do curso (2018/1), momento de uso do Padlet para construção do conhecimento sobre conteúdos básicos de informática.

Como instrumento de coleta de dados na etapa 2, foi aplicado questionário online e, na etapa 4, foram feitos registros de depoimentos nos murais virtuais (Padlet) de cada aluno/professor.

Cada aluno/professor matriculado teve como atividade inicial construir um 
Padlet específico para servir de caderno digital. Os professores matriculados nocurso

tinham faixa etária de 30 a 40 anos, todos com ensino superior completo, na área de formação de professores (licenciatura), sendo a grande maioria no curso de Pedagogia. O autor Prensky (2001) apresenta uma discussão que define bem o perfil dos professores matriculados no curso de extensão de informática instrumental. Prensky (2001, p.3) fala que "Aqueles que não nasceram no mundo digital, mas em alguma época de nossas vidas, ficou fascinado e adotou muitos ou a maioria dos aspectos da nova tecnologia são, e sempre serão comparados a eles, sendo chamados de Imigrantes Digitais."

\section{Análise dos dados}

O curso teve uma proposta com características próprias, um desenho pedagógico em movimento, ou seja, foram duas versões - uma em cada semestre - em que na segunda versão optou-se pelo uso de um espaço digital como apoio ao ensino e aprendizagem.

Para melhor organização da apresentação dos dados encontrados e por questões de ética de pesquisa, os sujeitos serão chamados de codinomes de letras do alfabeto brasileiro. A primeira etapa de coleta e análise de dados mostrou escolas públicas com estrutura físicas extremamente precárias, na sua grande maioria sem acesso à Internet. $\mathrm{Na}$ segunda etapa de coleta e análise de dados os profissionais da educação revelaram suas carências quanto ao uso da tecnologia no cotidiano, conforme pode ser observado na tabela a seguir, com alguns depoimentos de alguns alunos do curso:

Tabela 1 - respostas dos alunos sobre conhecimento prévio de informática

\begin{tabular}{|l|ll|}
\hline Sujeito A & Não tenho muito conhecimento com a informática & \\
\hline Sujeito B & Na verdade tenho poucos conhecimentos na área & \\
\hline Sujeito C & $\begin{array}{l}\text { Pouquíssimos conhecimentos, apenas uso o computador para o } \\
\text { básico.Muitas vezes necessito da ajuda das colegas de trabalho }\end{array}$ & \\
\hline Sujeito D & $\begin{array}{l}\text {.. tenho dificuldade em baixar alguns conteúdos e salvar imagens com qualidade e na } \\
\text { edição de vídeos e áudios. }\end{array}$ \\
\hline Sujeito E & $\begin{array}{l}\text { Ainda não tenho domínio sobre alguns procedimentos usados no teclado. Espero } \\
\text { aprender copiar e colar, trabalhar com o Word, sabendo formatar usando a regras da } \\
\text { ABNT. }\end{array}$ \\
\hline
\end{tabular}

$\mathrm{Na}$ terceira etapa de coleta e análise dos dados foi realizado um levantamento das plataformas LMS e dos recursos possíveis de uso como ambiente virtual de aprendizagem. Os critérios para análise da plataforma e espaço digital eram ser colaborativa, possibilitar interação e ser gratuita. Na tabela a seguir são apresentados os espaços e plataformas analisados:

Tabela 2 - Lista de espaços e plataformas analisados

\begin{tabular}{|c|c|}
\hline Espaço digital & Plataforma LMS \\
\hline Padlet & Moodle \\
\hline Pbworks & Rooda \\
\hline Facebook & Canvas \\
\hline
\end{tabular}




\begin{tabular}{|c|c|}
\hline Easel & LAMS \\
\hline Visme & LCDS \\
\hline & Co-laborando \\
\hline & Classroom \\
\hline
\end{tabular}

Nesse momento de análise dos espaços e plataformas digitais foi feito um levantamento de experiências sobre uso de espaços digitais em que foram identificados artigos sobre uso do Padlet como apoio pedagógico. Foram identificados 5 relatos de experiências publicados, entre os anos de 2016 e 2017, em formato de artigos, sendo 2 sobre ensino da língua inglesa (Ana Osorio Coelho) e (Zenaide Moschim Gianini Fatec Mogi Mirim), 1 sobre ensino da língua espanhola (Iara Rodrigues de Oliveira, Gilse Morgental Falkembac), 1 sobre ensino de filosofia (Luis Fernando Lima e Silva), 1 sobre formação tecnológica (Karine Matos Mota).

As leituras dos relatos de experiências anteriores sobre uso do Padlet como recurso pedagógico contribuiu para escolha do mesmo como ambiente virtual de aprendizagem para curso. $\mathrm{O}$ recurso apresenta layout de fácil navegação para usuário e pode ser utilizado como espaço de apoio aos professores ou espaço específico do aluno, conforme pode ser observado nas imagens a seguir:

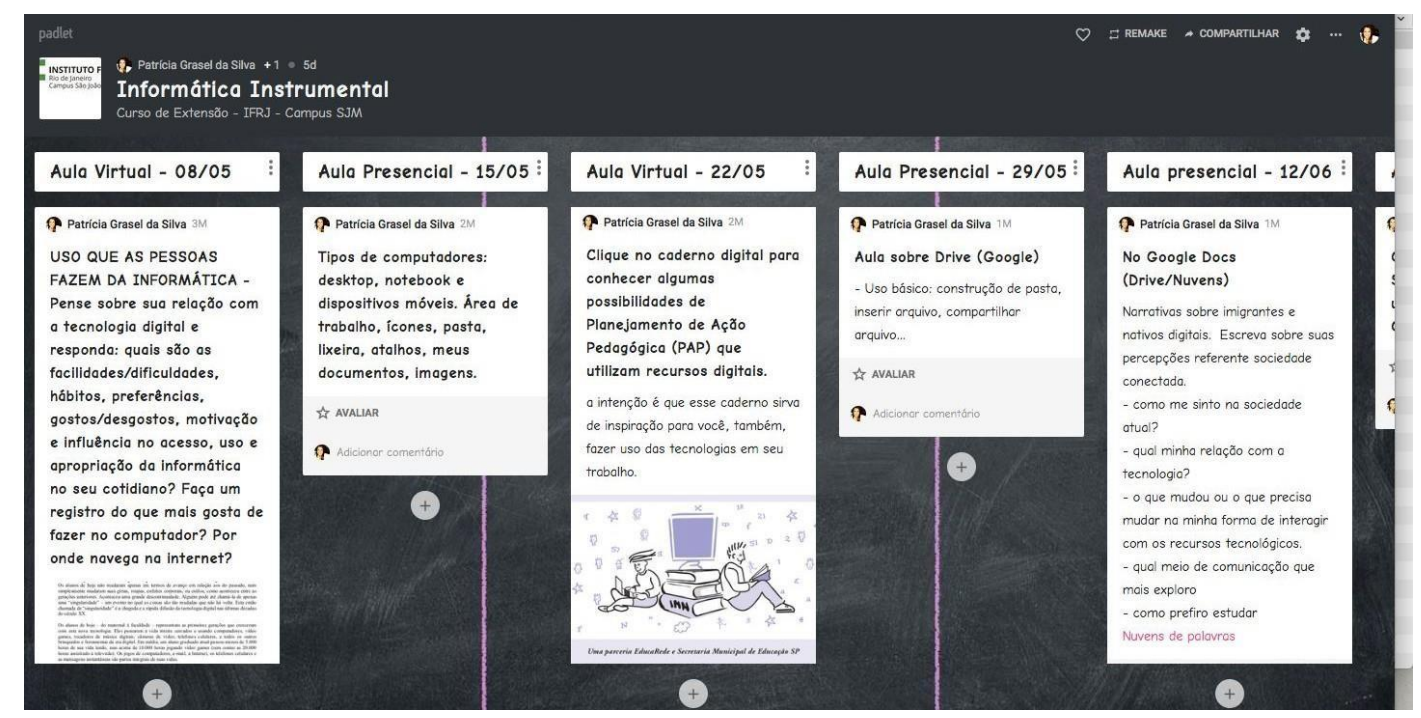

Figura 1 - Padlet utilizado como espaço do professor 


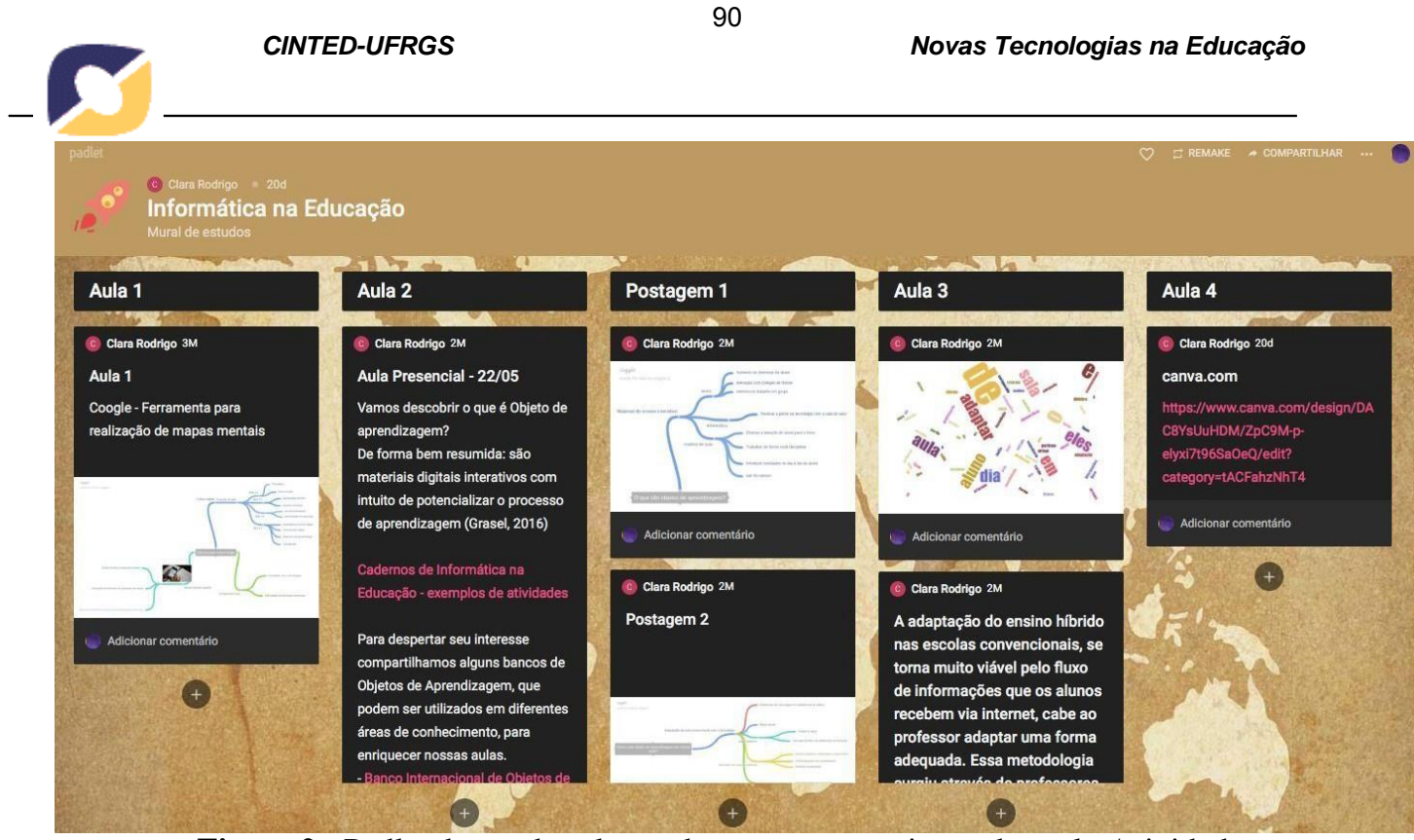

Figure 2 - Padlet de um dos alunos do curso com registros das aulas/atividades

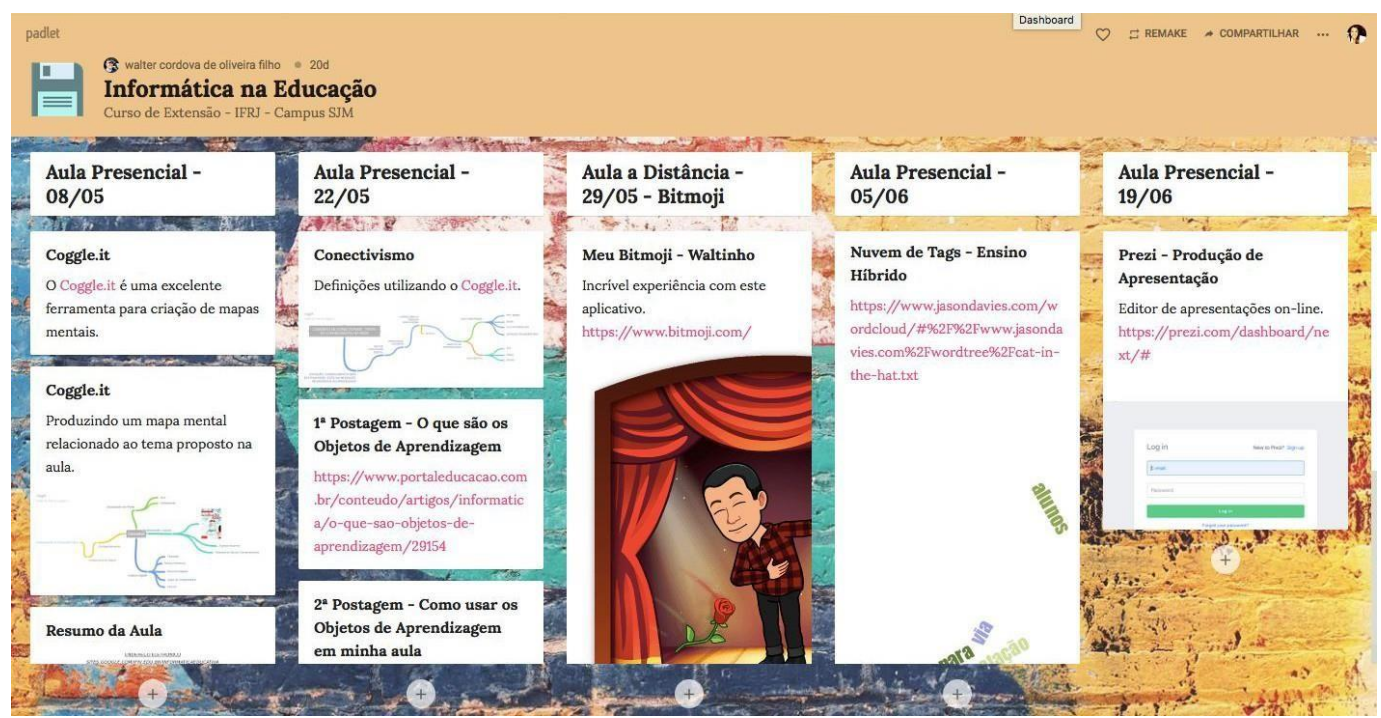

Figure 3 - Padlet de um dos alunos do curso com registros das aulas/atividades

O curso foi organizado com 8 atividades à distância, orientadas através do Padlet e 8 atividades presenciais orientadas em aula pelos professores do curso. Conforme observado pelos depoimentos dos alunos na segunda etapa, os mesmos apresentavam carências de conhecimento e insegurança quanto ao uso básico do computador. No entanto, $100 \%$ das atividades propostas foram $100 \%$ realizadas. Todas as atividades orientadas através do Padlet foram desenvolvidas a distância pelos alunos, o que revela o papel social do recurso como ambiente virtual de aprendizagem, pois serve como espaço digital para organização do desenho metodológico das aulas, compartilhamento de materiais diversos e interação entre sujeito e objeto de conhecimento através dos curtir, comentar e avaliar as postagens dos conteúdos publicados.

Todos os alunos ao realizar as atividades demonstraram facilidade de navegação pelo Padlet e compreensão da lógica dos hiperlinks. Ao longo do curso nenhum aluno demonstrou dificuldade em realizar a atividade em consequência da usabilidade do Padlet. Todas as dúvidas referentes ao uso do recurso eram comentadas em aula presencial, não tendo nenhum registro de dúvidas quanto questões técnicas.

A análise das etapas realizadas até o momento revelam que o relato de 
experiência sobre o uso de um recurso on-line, colaborativo e gratuito que apresenta fácil navegação, o que contribui com a aprendizagem do aluno no ciberespaço, por não ocupar-se com aspectos de domínio técnico. Sendo assim, considera-se que o Padlet é um recurso com potencial para ser usado como ambiente virtual de aprendizagem.

\section{Considerações finais}

Entre a primeira e a segunda versão do curso houve um levantamento e análise das necessidades e carências apresentadas pelos alunos. Dentre tais constatações, foram identificadas fragilidades quanto ao uso básico do computador em detrimento ao uso da tecnologia na educação. Os alunos mostraram urgência para conhecer e se apropriar da navegação na internet e usabilidade.

Diante desta realidade apresentada optou-se por usar como plataforma na formação de professores um ambiente digital com navegação simples, fácil e intuitiva, com recursos específicos para compartilhamento de materiais e possibilidade de interação. Como utilizar uma plataforma e-learning exigiria adaptação inicial dos alunos e o curso desenvolvido se tratava de uma extensão com carga horária baixa, buscou-se "fugir" das plataformas formais de educação a distância. Considerou-se então, que muitos alunos ainda estavam em processo de apropriação básica do computador para, em paralelo, se preocuparem com apropriação de um ambiente virtual de aprendizagem.

$\mathrm{O}$ que se constatou com uma facilitação da navegabilidade do aluno na internet, possibilitando-lhe uma experiência mais amigável e intuitiva, inclusive sem fazer uso de políticas de acesso, como login e senha, presentes em boa parte das plataformas educacionais. Acredita-se que, devido resultados das análise dos dados, usar uma plataforma e-Learning específicas poderia dificultar a autonomia $\mathrm{e}$ organização no processo de aprendizagem. Os alunos demonstraram interesse em dar continuidade de uso ao Padlet mesmo após o final do curso, o que será objeto de análise para as próximas etapas do projeto de pesquisa. $\mathrm{O}$ trabalho apresentado prevê outras edições do curso, justamente para verificar os resultados pedagógicos do uso do Padlet nas práticas dos professores. Por ora é possível afirmar que o recurso serve como ambiente virtual de aprendizagem por apresentar um layout amigável, com ferramentas de fácil navegação pelo usuário o que considera-se que contribuí significativamente para o desenvolvimento de autonomia e organização dos alunos diante do processo de formação no ciberespaço.

\section{Referências}

BEHAR, Patricia (org.). Competências em Educação a Distância, editora Penso, Porto Alegre/RS, 2013

CASTELLS, Manuel. A sociedade em rede. São Paulo: Paz e Terra, 1999

CARLOTTO, Fabiane - Internet: oceanos de informação. In FERREIRA, Lenira Weil (org.) Leituras, significações plurais: educação e mídia: o visível, o ilusório, a imagem. Porto Alegre, RS. editora EDIPUCRS, 2003.

MOORE, Michel G. KEARSLEY, G. Educação a distância: uma visão integrada. Editora Cengage Learning. São Paulo, 2011

LÉVY, Pierre. O que é virtual. Rio de Janeiro: Editora 34, 1996. 
. A inteligência coletiva: por uma antropologia do ciberespaço. 2. ed.

Tradução de Luiz Paulo Rouanet. São Paulo: Loyola, 1999.

. As tecnologias da inteligência: o futuro do pensamento na era da informática. Tradução de Carlos Irineu da Costa. São Paulo: Editora 34, 1993

PRENSKY, Marc. Nativos Digitais, Imigrantes Digitais. De On The Horizon - NCB University Press, Vol. 9, n5, out. 2001.

SILVA, Patrícia G. S.; TEIXEIRA, Adriano C., CARVALHO, Marie J. S "Relato da experiência de uma Arquitetura Pedagógica em sala de aula". RENOTE. Revista Novas Tecnologias na Educação, v. 1, p. 1-10, 2009.

TEIXEIRA, Adriano C.; CARVALHO, Marie J. S.; SILVEIRA, Patrícia G. S. “A virtualização da aprendizagem: novas perspectivas na cibercultura”. Revista Brasileira de Computação Aplicada, v. 1, p. 45-52, 2009. 